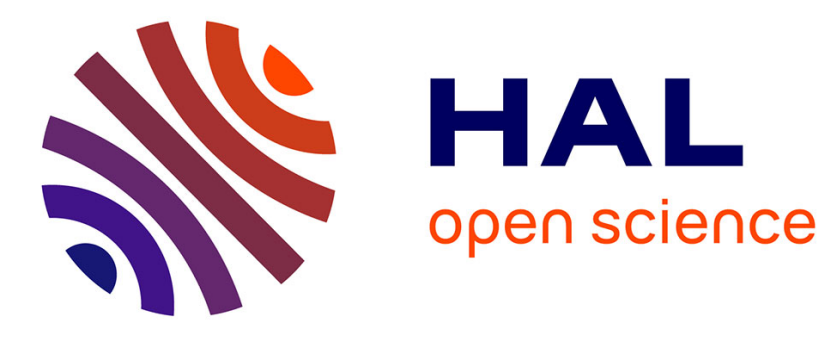

\title{
An in situ IR-Vis Sum Frequency Generation Spectroscopy study of cyanide adsorption during zinc electrodeposition
}

F. Rossi, M. Bevilacqua, Bertrand Busson, M. Corva, A. Tadjeddine, F. Vizza, E. Vesselli, B. Bozzini

\section{To cite this version:}

F. Rossi, M. Bevilacqua, Bertrand Busson, M. Corva, A. Tadjeddine, et al.. An in situ IR-Vis Sum Frequency Generation Spectroscopy study of cyanide adsorption during zinc electrodeposition. Journal of Electroanalytical Chemistry, 2019, 855, pp.113641. 10.1016/j.jelechem.2019.113641 . hal02368279

\section{HAL Id: hal-02368279 \\ https://hal.science/hal-02368279}

Submitted on 9 Jun 2020

HAL is a multi-disciplinary open access archive for the deposit and dissemination of scientific research documents, whether they are published or not. The documents may come from teaching and research institutions in France or abroad, or from public or private research centers.
L'archive ouverte pluridisciplinaire HAL, est destinée au dépôt et à la diffusion de documents scientifiques de niveau recherche, publiés ou non, émanant des établissements d'enseignement et de recherche français ou étrangers, des laboratoires publics ou privés. 


\title{
An in situ IR-Vis Sum Frequency Generation Spectroscopy study of
}

\section{cyanide adsorption during zinc electrodeposition}

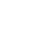

\author{
F. Rossi ${ }^{1}$, M. Bevilacqua 2 , B. Busson ${ }^{3}$, M. Corva ${ }^{4,5}$,
}

A. Tadjeddine ${ }^{3}$, F. Vizza ${ }^{2}$, E. Vesselli ${ }^{4,5}$, and B. Bozzini ${ }^{{ }^{*}}$

${ }^{1}$ Dipartimento di Ingegneria dell'Innovazione, Università del Salento, via Monteroni, 73100 Lecce (Italy)

${ }^{2}$ ICCOM CNR URT, via L. Giorgieri 1, 34127 Trieste (Italy)

${ }^{3}$ Laboratoire de Chimie Physique, CNRS, Univ. Paris-Sud, Université Paris-Saclay, Bâtiment 201 P2, 91405

Orsay (France)

${ }^{4}$ Dipartimento di Fisica, Università degli Studi di Trieste, via Valerio 2, 34127 Trieste (Italy)

${ }^{5}$ CNR-IOM, Area Science Park, S.S. 14 km 163.5, 34149 Basovizza (Trieste, Italy)

*corresponding author: benedetto.bozzini@unisalento.it

\section{Abstract}

In this paper, we demonstrate the feasibility of in situ non-linear IR-Vis Sum Frequency Generation (SFG) Spectroscopy investigations at zinc surfaces in electrochemical ambient. We investigated both zinc electrodeposition onto an extraneous electrode and adsorption on polycrystalline zinc. Electrodeposition studies were carried out onto a polycrystalline gold cathode in contact with a Zn-cyanocomplex solution containing free $\mathrm{CN}^{-}$, while adsorption studies were carried out on a polycrystalline zinc electrode in contact with a free- $\mathrm{CN}^{-}$solution. In both experiments, we monitored the spectroscopic features associated with the internal stretching of the adsorbed cyanide $\left(\mathrm{ca} .2100 \mathrm{~cm}^{-1}\right)$ that we exploited as local Au and $\mathrm{Zn}$ site probes. Spectroelectrochemical results were complemented by cyclic voltammetric measurements. This proof-ofprinciple study is encouraging in the view of more concrete applications regarding additive adsorption at zinc electrodes, aiming at a fundamental understanding of the cycling stability of zinc battery anodes.

\section{Introduction}

The electrochemical deposition of reactive metals is nowadays one of the most intensively studied processes in the field of electrochemical energetics, since it is the crucial step of the recharge of many secondary batteries, including metal-air devices. Specifically, interest in Zn electrodeposition from alkaline aqueous electrolytes has been recently revived owing, on the one hand, to the prospective technological importance of rechargeable metal-air batteries [1], and, on the other hand, to serious, so far unsolved, growth instability issues. In fact, the performance of rechargeable zinc-air batteries is largely limited by the low efficiency of the charging stage, due to formation of dendritic zinc structures, which cause short-circuits and capacity losses [2]. Quite a few electrochemical studies have been published in the field of zinc dendrite suppression, mainly based on the use of additives of either organic or inorganic nature (e.g. $[3,4]$ ). However, they are mainly empirical investigations aiming at establishing correlations among particular cases, rather than general physico-chemical tools for a knowledge-based control of the process. In order to overcome this gap, 
fundamental studies are still necessary on the different steps leading to 3D crystallite growth: (i) reduction of the electroactive complexes, (ii) nucleation both on the extraneous cathode substrate and on predeposited zinc, (iii) subsequent growth, (iv) adsorption of additives and ligands on the dynamically growing zinc layer. Specifically, in situ vibrational spectroscopies can be exploited in order to study the interaction of electrolyte components, such as additive molecules, and electroactive complexes - their ligands, in particular - at the cathodic interface at different stages of the zinc growth. In the case of zinc electrodeposition from alkaline aqueous solutions, to the best of the Authors' knowledge, only one paper has been published on in situ Surface Enhanced Raman Spectroscopy (SERS) study of triethanolamine (TEA) as an additive [5]. Notwithstanding the technical appeal of working with a visible light beam, SERS can be implemented only on nanostructured surfaces that are not always easy to obtain. To overcome this issue, IR-Vis Sum-Frequency Generation Spectroscopy (IR-Vis SFG) can be exploited. IR-Vis SFG is a non-linear spectroscopic technique, which is intrinsically sensitive to interfaces. This property implies that, at variance with FT-IR techniques, SFG does not require the acquisition of differential spectra for potential-dependent in situ work. Of course, the necessity of acquiring successively at least couples of spectra poses stringent requirements on the stationarity of the process being investigated, that can barely be ensured in an electrodeposition experiment. In situ SFG has been used for the investigation of a series of electrodeposition processes of $\mathrm{Au}, \mathrm{Ag}$, and $\mathrm{Cu}$ based alloys from both aqueous and non-aqueous electrolytes $[6,7]$, but it has never been attempted for that of reactive metals. Nevertheless, publications reporting electrochemical SFG data collected in situ during the corrosion of Co- and W-based alloys [8] bear promise that even a dynamic electrochemical interface can be successfully monitored with this approach. Moreover, literature on ex situ SFG measurements of zinc corrosion brings support to the feasibility of studying the vibrational properties of the zinc/electrolyte interface with this method [9]. In this work we studied zinc electrodeposition on a gold cathode from a $\mathrm{Zn}$ (II)cyanocomplex solution with IR-Vis SFG spectroscopy, monitoring cyanide adsorption during electrodeposition. As starting points for the $\mathrm{Zn}$ electrodeposition work, we studied the adsorption of $\mathrm{CN}^{-}$in situ on polycrystalline Au and Zn electrodes. For comparison, work on the Au electrode was carried out under the same static and dynamic conditions employed for $\mathrm{Zn}$ electrodeposition, both in the absence and in the presence of $\mathrm{Zn}(\mathrm{II})$ cyanocomplexes.

\section{Methodology}

\subsection{Electrochemical SFG setup}

A setup for in situ and operando electro-chemical and catalytic IR-Vis SFG experiments was developed at the Visible and Infrared Spectroscopy Laboratory at the Physics Department of the University of Trieste [10]. The experiments take place in a dedicated three electrode electrochemical cell - consisting in a modification of the concept described in [11] - assembled on a holder, inside a black box, and controlled by a potentiostat (AMEL 551).

The body of the electrochemical cell for in situ SFG is made of polyvinyl chloride (PVC) and consists of different parts (see Figure 1): the electrolyte compartment, equipped with the appropriate electrical contacts for the working- (WE, 1), reference- (RE, 3) and counter-electrodes (CE, 4), a sample compartment (6), a vacuum pump tube to hold the WE in position by suction (2), and a calcium fluoride $\left(\mathrm{CaF}_{2}\right)$ prism (5). A copper screw present in the compartment (1) provides the electric contact of the WE with the potentiostat connections. The copper screw does not touch directly the WE, but it is connected to it by means of a helical platinum wire, reaching the bottom of the WE through an evacuated perforated plastic tube, terminated with an Oring seat, that is sealed by the WE itself, held in place by depression. The copper screw also allows the fine tuning of the WE distance with respect to the prism surface, in order to control the electrolyte thickness required for IR transmission. $\mathrm{An} \mathrm{Ag} / \mathrm{AgCl} \mathrm{RE}$ is fixed in its compartment by means of a screw. The $\mathrm{CE}$ is a 
wound platinum wire, exhibiting a surface area of $2 \mathrm{~cm}^{2}$ in contact with the electrolyte. The prism on the one hand seals the cell leaving an electrolyte gap of appropriate thickness and, on the other hand, drives the impinging Vis and IR beams to the WE surface and channels the resulting SFG beam to the detector. Moreover, two holes have been drilled into the prism away from the optical path of the three light beams to enable experiments in which the electrolyte can be continuously circulated by means of a peristaltic pump. This capability of the cell was not exploited in the present investigation. The cell holder is equipped with micrometric screws, allowing fine positioning along 6 degrees of freedom, in order to optimize the alignment of the WE with the light beams. The holder allows the following movements: (i) in-plane along the $x$ and $y$ directions, parallel to the sample surface; (ii) vertical, in the $z$ direction, normal to the sample surface; (iii) tilt around the $x$ and $y$ axes; (iv) azimuth around z.Potentiostatic tests in the SFG cell compared with similar ones carried out in a conventional, optimized three-electrode cell have shown that the ohmic drop is negligible in the current-density range of interest for electrodeposition work.

The box that encloses the electrochemical cell possesses a system of lenses, which drives the impinging IR and Vis beams to the sample surface at $55^{\circ}$ and $60^{\circ}$ with respect to the surface normal, respectively, with the desired polarization. The lenses drive the resultant SFG beam to the monochromator (MS2001) and to the photomultiplier tube detection system (Hamamatsu R7899). In the present study, all spectra were collected in the ppp polarization configuration (SFG-visible-infrared). The visible beam $(532 \mathrm{~nm}$ ) and the tuneable IR beam (1000-4500 $\left.\mathrm{cm}^{-1}\right)$ used for the SFG experiments are generated by means of an EKSPLA setup described in [10]. Data acquisition and instrument control are performed remotely via custom LabVIEW software interfaces.

\subsection{Data processing}

SFG spectra were analysed by least-squares fitting to a literature expression of the non-linear second order susceptibility (Eq. 1) [12], after normalization to the impinging visible and IR intensities, in order to remove the modulations caused by the laser instability and intrinsic to the IR generation process. In the case of raw spectra exhibiting a tilted background, we removed the slope and set the background level to its average. The non-resonant background originates indeed from the combination of the nonlinear responses of free and bound electrons in the metal [13-15] associated with plasmonic resonances, especially in the case of electrodeposition, that intrinsically generates nanocrystals [6]. This signal does not vary significantly with the IR frequency range of the measurements- (less than $200 \mathrm{~cm}^{-1}$ ), and can therefore be assumed as constant with reasonable accuracy. Indeed, for gold it is found to vary of a factor of three moving from 400 to $700 \mathrm{~nm}$ the visible excitation wavelength (i.e. spanning about $10^{4} \mathrm{~cm}^{-1}$ ) [13-15], The deconvolution yielding the SFG data plots is reported in [10]

Briefly, $A^{(N R)}$ and $A_{v}^{(R)}$ are the non-resonant and $v_{\text {th }}$-resonant amplitudes, respectively; $\Delta \phi_{v}$ is the phase difference between the $v_{\text {th }}$-resonant and non-resonant signals; $\Omega_{v}$ is the energy position of the line and $\Gamma_{v}$ is the resonance Lorentzian broadening, which is related to the decoherence time of the excited state. A Gaussian broadening was also considered by means of a convolution of the lineshape, mainly accounting for the inhomogeneity contributions in the adsorbed species population [16]. In this paper, the normalized SFG spectra (black dotted lines) are presented together with the corresponding best-fit function (red line), the deconvoluted components (color-filled profiles), and the residual (dark-yellow filled profiles). 


\subsection{Sample preparation}

In this study we employed Au and Zn WEs in the form of discs. The former metal was used as the a cathode for both adsorption and $\mathrm{Zn}$ electrodeposition from an aqueous cyanide solution. $\mathrm{Zn}$ discs were exploited instead for the adsorption studies. The polycrystalline gold WE used for the zinc electrodeposition studies (8 $\mathrm{mm}$ diameter) was cleaned with the following procedure before each experiment: (i) mechanical polishing with abrasive paper down to 1200 grit and with $1 \mu \mathrm{m}$ diamond paste; (ii) immersion for 5 min in a concentrated solution of nitric acid $\left(69.5 \% \mathrm{HNO}_{3}\right)$ to remove organic contaminants; (iii) rinsing with milli-Q water; (iv) annealing in a butane flame to red colour, followed by quenching with milli-Q water (the flamingquenching sequence was repeated at least three times); $(v)$ the cleaned WE was protected with a drop of ultra-pure water and transferred to the electrochemical cell without direct exposure to air. The polycrystalline zinc WE ( $9 \mathrm{~mm}$ diameter) was mechanically polished as described above and electrochemically cleaned in situ in the measurement cell, potentiostatically, in the range of the hydrogen evolution reaction (HER) for about 20 minutes.

\subsection{Electrolytes}

We employed free $\mathrm{CN}^{-}$-based aqueous electrolytes: a $\mathrm{Zn}$ (II)-cyanocomplex bath containing free $\mathrm{CN}^{-}$for the electrodeposition studies and a $\mathrm{CN}^{-}$solution for adsorption investigations on $\mathrm{Au}$ and $\mathrm{Zn}$. The $\mathrm{CN}^{-}$solutions were obtained by dissolving $25 \mathrm{mM} \mathrm{KCN}$ and $0.1 \mathrm{M} \mathrm{NaClO}_{4}$ in milli-Q water or by prolonged cathodic reaction of $25 \mathrm{mM}$ 4-cyanopyridine in the same perchlorate supporting electrolyte [17]. The cyanocomplex bath was obtained by dissolving $5 \mathrm{mM} \mathrm{ZnO}$ to the $\mathrm{KCN}$ solution, whereby the $\mathrm{Zn}$ (II) cyanocomplex forms spontaneously.

\subsection{Electrochemical measurements}

Cyclic voltammetry (CV) experiments were performed with polycrystalline $\mathrm{Au}$ and $\mathrm{Zn}$ electrodes in contact with the solutions employed for SFG measurements and, in addition, with the $\mathrm{NaClO}_{4} 0.1 \mathrm{M}$ supporting electrolyte, for comparison. Moreover, calibration runs were performed also with $\mathrm{HClO}_{4} 0.1 \mathrm{M}$ : but are not reported for brevity. The working electrodes and their preparation methods were the same used for SFG. The measurements were carried out in a conventional three-electrode cell, equipped with an Au wire counter-electrode and an $\mathrm{Ag} / \mathrm{AgCl}(\mathrm{KCl} 3 \mathrm{M})$ reference electrode. All potentials in this work are reported on the $\mathrm{Ag} / \mathrm{AgCl}$ scale. In order to highlight small voltammetric features in the cathodic range, the solutions were deaerated by $\mathrm{N}_{2}$ bubbling before the measurement and an $\mathrm{N}_{2}$ blanket was kept during the CV measurement. The scan rate was $100 \mathrm{mV} \mathrm{s}^{-1}$.

\subsection{Experiments design}

The ultimate goal of this investigation is to achieve a better understanding at the molecular level of the zinc growth process by in situ monitoring of the adsorption of $\mathrm{CN}^{-}$, the cyanocomplex ligand, present in the bath in excess, as customary in alkaline metal plating baths. In the cyanoalkaline $\mathrm{Zn}$ bath chemistry, $\mathrm{CN}^{-}$acts at the same time as the ligand of the metal electroactive species and as a probe-molecule of the dynamic state of the growing metal surface. In analogy with our previous in situ SERS study of a similar system [5], the experiment was performed starting with a clean polycrystalline gold surface $\left(\mathrm{Au}_{\text {poly }}\right)$ immersed in a $\mathrm{Zn}$ cyanocomplex solution containing free $\mathrm{CN}^{-}$(see Section 2.4), from which zinc can be deposited by means of an appropriate cathodic bias. Even though the aim of our study is to follow the zinc growth, for reference after the protocol, developed in [5] - we also investigated $\mathrm{CN}^{-}$adsorption on the Au cathode from the $\mathrm{Zn}$ (II)free solution. The electrochemical behaviour of this system is well known in the literature [18] and represents 
the benchmark against which the zinc growth process was studied, by contacting the Au cathode with the $\mathrm{Zn}$ (II)-cyanocomplex bath and electrodepositing $\mathrm{Zn}$ by means of an applied bias. Both experiments were carried out at three applied bias values: $-700,-920$ and $-990 \mathrm{mV}$. We chose these potentials because they are related to three specific electrochemical conditions with respect to the $\mathrm{Zn}$ electrodeposition process. At -700 $\mathrm{mV}$ electrodeposition does not occur, while at $-920 \mathrm{mV}$ electrodeposition takes place at a low rate, and at $990 \mathrm{mV}$ electrodeposition runs at a relatively high rate, compared with our data collection time: indeed, we chose those specific deposition potentials in order to define growth speeds that are compatible with the acquisition rate of the spectrometer (ca. $15 \mathrm{~min}$ per spectrum). SFG spectra were collected, at each potential, in the $2030 \div 2170 \mathrm{~cm}^{-1}$ wavenumber range, associated with the $\mathrm{C} \equiv \mathrm{N}$ internal stretching mode. The experimental protocol consisted in starting with a freshly flame-annealed Au surface, applying a potentiostatic polarization of $-700 \mathrm{mV}$ for ca. $30 \mathrm{~min}$, and then stepping to a selected more cathodic potential to record the SFG spectra sequentially in time. $\mathrm{CN}^{-}$adsorption onto bulk polycrystalline $\mathrm{Zn}$ was studied at OCP $(-830 \mathrm{mV})$ and at $-1250 \mathrm{mV}$. SFG spectra were collected at each potential in the $2030 \div 2250 \mathrm{~cm}^{-1}$ wavenumber range.

\section{Results}

\subsection{Cyclic voltammetry}

Figure 2 reports the CV curves recorded with a polycrystalline $A u$ electrode in contact with (1) the pure supporting electrolyte $0.1 \mathrm{M} \mathrm{NaClO}_{4}$ ), (2) $0.1 \mathrm{M} \mathrm{NaClO}_{4}+25 \mathrm{mM} \mathrm{KCN}$, and (3) $0.1 \mathrm{M} \mathrm{NaClO}_{4}+25 \mathrm{mM} \mathrm{KCN}+$ $5 \mathrm{mM} \mathrm{ZnO}$. The black curves show the electrochemical behaviour of $\mathrm{Au}$ and span both cathodic and anodic conditions, while the red curves focus on the potential range specifically investigated in the SFG experiments. The voltammogram recorded in the pure supporting electrolyte (curve (1)) exhibits an evident electrochemical window that spans the potential range limited by the features $A, B_{a}$, and $B_{c}$. The former corresponds to the onset of the hydrogen evolution reaction, the latter two to the formation (anodic branch: $\mathrm{B}_{\mathrm{a}}$ ) and the reduction (cathodic branch: $\mathrm{B}_{\mathrm{c}}$ ) of an Au oxide film, respectively. In the double-layer charging region, small features can be noticed, corresponding to well-known potential-dependent restructuring of the Au surface $[19,20]$. At higher anodic potentials the oxygen evolution reaction onset can be noticed (feature C). Moreover, a slight oxygen reduction reaction background is observed for potentials more cathodic than ca. $-0.5 \mathrm{~V}$. The addition of KCN (curve (2)) leads to the disappearance of features B and to the growth of two different cathodic features $\left(D_{c}, E_{c}\right)$ and three new anodic ones $\left(D_{a 1}, D_{a 2}, E_{a}\right)$. $D_{a 1}$ and $D_{a 2}$ correspond to the formation of $\mathrm{Au}(\mathrm{I})$ cyanocomplexes, the former peak is due to the growth a pseudo-passivating film of insoluble $\mathrm{AuCN}$, while the latter shoulder correlates with gold dissolution in the form of soluble $\mathrm{Au}(\mathrm{CN})_{2}^{-}$. On the cathodic side, peak $D_{c}$ correlates to the reduction of the $A u(I)$ film. The nature of peak $E_{c}$ is slightly different, depending on whether the anodic terminal potential (ATP) reaches the Au oxidation range or not. In the former case, since no $\mathrm{Au}(\mathrm{CN})_{2}{ }^{-}$is present in the solution, $\mathrm{E}_{\mathrm{c}}$ corresponds merely to cathodic desorption of $\mathrm{CN}^{-}$from the metallic Au surface. In the latter case, in which the peak is also more pronounced and broader, desorption of $\mathrm{CN}^{-}$takes place together with the faradaic reaction of $\mathrm{Au}(\mathrm{CN})_{2}{ }_{2}^{-}$reduction to elemental $\mathrm{Au}$ (equilibrium potential: $-820 \mathrm{mV}$ ). Finally, peak $\mathrm{E}_{\mathrm{a}}$ denotes $\mathrm{CN}^{-}$adsorption onto the metallic Au surface. More details on the electrochemistry of the $\mathrm{Au} / \mathrm{CN}^{-}$system can be found in already published literature [6, 21]. The presence of both $\mathrm{CN}^{-}$and $\mathrm{Zn}^{2+}$ (curve (3)) leaves peaks $\mathrm{D}_{c}$ and $\mathrm{D}_{\mathrm{a} 2}$ essentially unmodified, while peak $D_{a 1}$ splits into two, probably owing to the formation of a monolayer of $\mathrm{Zn}$-alloyed Au. This phenomenon is known in perchlorate solutions with a range of anions [22, 23], but the specific case of $\mathrm{CN}^{-}$has not been addressed in the literature yet. Nevertheless, the formation of a second peak, ca. $0.25 \mathrm{~V}$ more anodic that the Au-oxidation one, is compatible with a process of this type. Peak $E_{c}$ is still present and again a dependence in peak position and shape on the ATP is found, as in the case of the solution containing only $\mathrm{CN}^{-}$. This peak is modified by the presence of $\mathrm{Zn}^{2+}$, owing to the fact that $\mathrm{Zn}$ deposition from uncomplexed $\mathrm{Zn}^{2+}$ occurs in this potential range, as also witnessed by the formation of an evident $\mathrm{Zn}$ layer by potentiostatic deposition 
in this potential range. This is further confirmed by shifting the cathodic terminal voltage to $-1.5 \mathrm{~V}$, where $\mathrm{Zn}$ electrodeposition from complexed $\mathrm{Zn}^{2+}$ occurs (see inset of Figure 2). It can be noticed that the cathodic branch of the voltammogram is not modified above $-1.2 \mathrm{~V}$, but in the anodic one new anodic stripping features appear (F) due to previous bulk $\mathrm{Zn}$ deposition from the more abundant complexes.

In Figure 3 we show the CVs measured with a polycrystalline $\mathrm{Zn}$ electrode in contact with (1) the pure supporting electrolyte $0.1 \mathrm{M} \mathrm{NaClO}_{4}$, and (2) $0.1 \mathrm{M} \mathrm{NaClO}_{4}+25 \mathrm{mM} \mathrm{KCN}$. The black lines describe the behaviour of $\mathrm{Zn}$ in the potential range encompassing $\mathrm{Zn}$ corrosion and HER, while the red curves correspond to the conditions employed for the SFG experiments. The CV recorded with the pure supporting electrolyte in the wider potential window exhibits a couple of cathodic peaks $\left(C_{1}, C_{2}\right)$ and an anodic one $(A)$, in addition to Tafel-type current density growth regions corresponding to $\mathrm{Zn}$ corrosion (B) and HER (D). The anodic peak $A$ is suppressed if the CTP (cathodic terminal potential) is set to $-1.25 \mathrm{~V}$. Coherently with the literature [24], the peaks can be assigned to the corresponding processes. In the specific: (A) passivation of the $\mathrm{Zn}$ film by $\mathrm{ZnO}$ precipitation; (B) transpassive corrosion of $\mathrm{Zn}$, releasing $\mathrm{Zn}^{2+}$ into the electrolyte; $\left(\mathrm{C}_{1}\right)$ : reduction of $\mathrm{Zn}^{2+}$ ions in solution; $\left(C_{2}\right)$ : reduction of the $\mathrm{ZnO}$ film. The reason why peak $A$ is suppressed when the cathodic potential is reversed at $-1.25 \mathrm{~V}$, is that the $\mathrm{ZnO}$ film is still stable in the relevant potential range and only transpassive processes can take place. The same features are found also in the presence of $\mathrm{CN}^{-}$in solution, but they are less evident in the latter case, witnessing anion adsorption in the whole investigated potential range. To the best of the authors' knowledge, no literature has been published regarding the interaction of $\mathrm{CN}^{-}$with $\mathrm{Zn}$ surfaces: a hint to corrosion protection afforded by $\mathrm{CN}^{-}$can be gleaned from a patent addressing the synergy of cyanide and $\mathrm{Hg}$ as corrosion inhibitors for $\mathrm{Zn}$ anodes [25].

\subsection{SFG investigation of $\mathrm{CN}^{-}$adsorption at a polycrystalline gold surface}

In Figure 4 we show the spectra collected as a function of time at $\mathrm{V}_{\text {bias }}$ in the range $-700 \div-990 \mathrm{mV}$. Panels (a) and (b) report time series of spectra measured at -920 and $-990 \mathrm{mV}$ respectively. The measurements at each potential were recorded starting from a freshly prepared Au surface. The potential was initially set to -700 $\mathrm{mV}$ for ca. $30 \mathrm{~min}$ (top spectrum in panel (a)), yielding stationary spectroscopic conditions, and then it was stepped at the selected value. Time zero corresponds with the application of the latter bias step. All the spectra of both series could be fitted with a single vibronic resonance, assigned to the internal stretching of $\mathrm{C} \equiv \mathrm{N}$ adsorbed via the carbon atom. At $-700 \mathrm{mV}$ the resonance is positioned at $2110 \div 2111 \mathrm{~cm}^{-1}$ and, on the basis of the literature ([26] and references therein), can be associated with $\mathrm{CN}^{-}$adsorbed on a partially oxidized gold surface resulting from exposure of $\mathrm{Au}$ to the aerated $\mathrm{CN}^{-}$solution [18]. Upon stepping the bias to -920 and $-990 \mathrm{mV}$ the resonance shifts to $2101.0 \pm 0.5$ and at $2085.8 \pm 0.5 \mathrm{~cm}^{-1}$, respectively. These values correspond to the internal stretching mode of the cyanide adsorbed on fully metallic gold and are coherent with the Stark shift values reported in the literature $[6,18]$. This spectroscopic scenario is also in line with the stabilization of metallic Au promoted by the cathodic potentials lower than $-700 \mathrm{mV}$. The time evolution of the lineshape parameters for the spectra of Figure 4 is plotted in Figure 5. Immediately after switching the potential to $-920 \mathrm{mV}$, the spectra show an evident redshift with respect to the $-700 \mathrm{mV}$ bias (Figure $4 \mathrm{a}$ and top of Figure 5a). The redshift becomes larger as a function of time and it is accompanied by a reduction of the peak amplitude. The time and bias spectral evolution is in perfect agreement with the progressive reduction of the Au surface caused by the applied cathodic potential: related mechanistic details can be found in [26]. A progressive decrease of the oxidative adsorption leads to the reduction of the intensity of both the resonant (bottom plot of Figure $5 \mathrm{a}$ ) and nonresonant amplitudes (bottom plot of Figure 5b). The Gaussian broadening, associated with the surface inhomogeneity, (top plot of Figure $5 \mathrm{~b}$ ) is essentially constant, thus excluding an evolution in time of the surface homogeneity or roughness at the atomic scale in this case. As hinted-at above, in the present case, in which Au reduction from an adsorbed $\mathrm{Au}(\mathrm{I})$ cyanocomplex takes place [26], the non-resonant background is expected to exhibit a significant contribution from the electronic excitations at the metal surface caused by the interaction of the gold sample with the Vis beam [13-15]. Thus, during the transient stage, a modification of the surface electronic properties occurs and 
is observed in situ: this optical response is in matching with the reduction of the Au surface, caused by the applied cathodic polarization. Panels (c) and (d) of Figure 5 report the corresponding spectral time-evolution for the time series collected at $\mathrm{V}_{\text {bias }}=-990 \mathrm{mV}$. In this case - corresponding to a higher cathodic bias and consequently higher Au-reduction rate - the evolution of the system is notably faster and, when compared with the spectral acquisition time, so that only a very limited cathodic peak shift can be observed in this timeseries. Stationary conditions are essentially attained already after the collection of the first few spectra.

\subsection{SFG investigation of $\mathrm{CN}^{-}$adsorption at a growing $\mathrm{Zn}$ surface during electrodeposition}

Similar experiments have been performed with $\mathrm{Zn}$ (II) cyanocomplexes present in the solution. Figure 6 reports spectra collected in the presence of $\mathrm{Zn}(\mathrm{II})$ in the potential range $-700 \div-990 \mathrm{mV}$, as a function of time. The spectroscopic scenario at $-700 \mathrm{mV}$ replicates that found in the absence of $\mathrm{Zn}(\mathrm{II})$, with negligible changes in the fit parameters: this is quite reasonable because on the one hand $\mathrm{Zn}$ (II) cannot react at this potential and, on the other hand, adsorption of free $\mathrm{CN}^{-}$is expected to be much stronger than that of the cyanocomplex.

The time evolution of the fit parameters of SFG spectra collected in situ during the Zn electrodeposition process is reported in Figure 7 for the two experiments performed at $-920 \mathrm{mV}\left(0.15 \pm 0.018 \mu \mathrm{A} \mathrm{cm}{ }^{-2}\right)$ and $990 \mathrm{mV}\left(12 \pm 4 \mu \mathrm{A} \mathrm{cm}{ }^{-2}\right)$. Of course, owing to the phase-formation process that is active at both potentials, increasing electrodeposition times at higher cathodic polarizations correspond to thicker $\mathrm{Zn}$ layers. In Figure 6 we also plot, in addition to the complete time series, the deconvolution of selected, representative spectra. The first result of the spectroscopic investigation is that all spectra, of both series, could be deconvoluted with two resonances constantly centred at 2099 and $2081 \mathrm{~cm}^{-1}$ that can be associated with the $\mathrm{CN}^{-} / \mathrm{Au}$ and $\mathrm{CN}^{-} / \mathrm{Zn}$ species, respectively. So, while in the absence of $\mathrm{Zn}$ a single resonance shifting in position with time was observed, when $\mathrm{Zn}$ deposition goes on we can distinguish two spectral contributions, associated with $\mathrm{CN}^{-}$adsorbed on the residual uncovered $\mathrm{Au}$ areas and at the $\mathrm{Zn}$ growing islands, partially covering the cathode. The resonance width associated with the decoherence time was kept fixed at $5.9 \mathrm{~cm}^{-1}$, the value found in the experiments described in Section 3.2. Indeed, in both cases the vibronic features are associated with the cyanide species, and it is reasonable to assume a similar coherent resonance lifetime in a first approximation in order to limit the number of degrees of freedom in the fitting procedure. Panel (a) of Figure 7 reports the time evolution of the phase and amplitude parameters for both resonances measured at -920 $\mathrm{mV}$. The resonant amplitude of the $\mathrm{CN}^{-} / \mathrm{Au}$ species is evidently a decreasing function of time, suggesting a progressive decrease of the bare $\mathrm{Au}$ area due to the growth of $\mathrm{Zn}$ islands. Of course, $\mathrm{CN}^{-} / \mathrm{Zn}$ species are absent at the beginning of the $\mathrm{Zn}$-growth experiment, starting with a clean Au cathode. With the progressive deposition of $\mathrm{Zn}$, the resonance amplitude associated with the $\mathrm{CN}^{-} / \mathrm{Zn}$ species initially increases, and, after ca. $100 \mathrm{~min}$ of electrodeposition, it starts to decrease, indicating that $\mathrm{CN}^{-}$tends to undergo cathodic desorption from thicker $\mathrm{Zn}$ layers. Electrodeposited $\mathrm{Zn}$ also clearly impacts the resonance phases. At the beginning of the experiment, where essentially only the $\mathrm{CN}^{-} / \mathrm{Au}$ species is present, the phase corresponds to the value found in the absence of $\mathrm{Zn}(\mathrm{II})$ in solution (see Section 3.1), typical of destructive interference with the non-resonant background, as expected for $\mathrm{CN} /$ Au layers. The progressive $\mathrm{Zn}$ growth gives rise to an initial, progressive formation of an Au-Zn surface alloy [5], followed by the evolution of a thicker, bulk Zn layer. Correspondingly, the relative phase value of the resonances increases, yielding constructive interference with the non-resonant background. This reflects in the different absorption properties of Au and $\mathrm{Zn}$ for the visible light, associated with very different electronic density of states close to the Fermi level. In particular, we observe that the phase evolution of the $\mathrm{CN} / \mathrm{Au}$ and $\mathrm{CN} / \mathrm{Zn}$ resonances is close to identical in the transition period corresponding to progressive $\mathrm{Zn}$ buildup (ca. 50-190 $\mathrm{min}$ ). In this time interval, we observe an almost constant dephasing of ca. $90-100^{\circ}$, suggesting that such phase evolution is controlled by the NR term, which consists in a mixture of contributions from $\mathrm{Au}$ and $\mathrm{Zn}$. In the specific, the phase difference between the resonance terms remains constant, thus pointing to an unchanged $C N$ bonding geometry, while both values 
shift progressively with respect to the NR phase term. The latter phenomenon reasonably indicates therefore that the electronic configuration of the electrode is progressively changing with the $\mathrm{Zn}$ deposition and growth.

Then, if we concentrate on zone II, it seems to me that the phase evolution is rather identical for both resonances. In other words, the dephasing between $\mathrm{CN} / \mathrm{Au}$ and $\mathrm{CN} / \mathrm{Zn}$ seems rather constant (or close to that) around $90-100^{\circ}$. So that would mean that 1) there is a constant dephasing between $\mathrm{CN}$ on $\mathrm{Zn}$ and $\mathrm{Au}$ and 2) the phase evolution is solely due to the nonresonant term, which consists of a mixture of NR from gold and NR from Zn.

The Gaussian width and the non-resonant amplitude, obtained from spectra measured at $-920 \mathrm{mV}$, are shown as a function of time in Panel (b) of Figure 7. Progressive modifications of the surface structure due to the deposition of zinc, reaching stationary conditions after ca. $100 \mathrm{~min}$, are compatible with the observed slight time-dependence of the Gaussian broadening, indicating increasing chemical and geometric inhomogeneity, and roughness of the electrode surface. The non-resonant background progressively decreases with time, since the deposited zinc induces modifications in the electronic properties of the surface. In the time series collected at $\mathrm{V}_{\text {bias }}=-990 \mathrm{mV}$ (Figure $7 \mathrm{~b}$ ), where the $\mathrm{Zn}$ growth rate is ca. three times higher than at $-920 \mathrm{mV}$, only one resonance could be resolved, that almost vanishes after ca. $150 \mathrm{~min}$ of electrodeposition. This is in agreement with the experiment performed at $-920 \mathrm{mV}$, since $\mathrm{CN}^{-}$tends to desorb cathodically from thick $\mathrm{Zn}$ layers. The cathodic desorption potential of $\mathrm{CN}^{-}$[20] and of cyanocomplexes [6] depends on the electronic structure of the adsorption bond that is in turn influenced by the metal substrate. Dedicated experiments and quantum-chemical computations would be needed for a better grasp over this process and are however beyond the scope of the present paper. Nevertheless, we can still say that anticipation of $\mathrm{CN}^{-}$desorption from $\mathrm{Zn}$ with respect to Au is expected owing to the lower electrochemical nobility of the former metal [27]. In the fitting procedure, the Gaussian width and phase value were fixed since already after 40 min the resonance almost vanished. Instead, we kept monitoring the NR and resonant amplitudes. The increase of the NR background is evident, suggesting a rearrangement of the surface where the growing $\mathrm{Zn}$ layers and residual bare gold terminations coexist.

\subsection{SFG investigation of $\mathrm{CN}^{-}$adsorption at a polycrystalline zinc surface}

Figure 8 shows the SFG spectra collected at OCP $(-830 \mathrm{mV})$ and at $-1.25 \mathrm{~V}\left(0.43 \pm 0.09 \mathrm{~mA} \mathrm{~cm} \mathrm{~cm}^{-2}\right)$ at the interface between a bulk $\mathrm{Zn}$ electrode and the free- $\mathrm{CN}^{-}$solution. In both cases, a resonance was clearly distinguished at $2101 \pm 3$ and $2104 \pm 5 \mathrm{~cm}^{-1}$, respectively, associated with the $\mathrm{C} \equiv \mathrm{N}$ internal stretching of cyanide adsorbed through the carbon atom. The relatively wide confidence intervals take origin from the rather low signal-to-noise ratio in the spectra due to the large amplitude of the non-resonant background and the low resonant signal from the low density adsorbate layer. This does not allow to distinguish the two peak positions and, in particular, to assess a Stark tuning, which is in any case expected to be limited owing to the weak interaction of the adsorbate with the reacting electrodic surface. Coherently with the analysis of the case of cyanide adsorption on Au, the HWHM $\Gamma$ was fixed to $5.9 \mathrm{~cm}^{-1}$, while the other parameters were optimized. Owing to the relatively low signal-to-noise ratio - due to the low surface coverage with adsorbed $\mathrm{CN}^{-}$for the reasons mentioned at the end of Section 3.2-, the quantitative value of the fit parameters is limited, and only the estimate of the resonance position can be rigorously trusted. Nevertheless, the presence of the $v\left(\mathrm{CN}^{-}\right.$ads $)$signal is evident already by inspection of the bare data and, from the point of view of in situ spectroscopy at the surface of a reactive metal, this fact is a notable achievement in its own right, since it proves the presence of the adsorbate at relatively high cathodic polarizations. In the electrolyte used for this study, OCP is a corrosion condition for $\mathrm{Zn}$ and the corresponding electrodic potential is rather 
negative. Moreover, the potential required to achieve a cathodic polarization is very close to the desorption potential of $\mathrm{CN}^{-}$from an Au surface. Still, in the absence of cathodic release of ligands due to the electrodeposition process, spectra of adsorbed $\mathrm{CN}^{-}$can be measured. This result is therefore promising in the view of a systematic in situ SFG investigation of $\mathrm{Zn}$ battery anodes during both charge and discharge processes.

\section{Conclusions}

The aim of this paper is to prove the feasibility of in situ electrochemical non-linear IR-Vis Sum Frequency Generation Spectroscopy (SFG) during Zn electrodeposition. In fact, SFG is highly appealing to investigate adsorption phases under electrochemical control and it is well known that adsorption of additives at the zinc anode surface is crucial, though poorly understood, for controlling the cycling stability of rechargeable zinc batteries [28]. The first demonstration has been based on the $\mathrm{Zn} / \mathrm{CN}^{-}$model system that, though not directly in connection with battery-related issues, nevertheless has a solid practical background in the field of alkaline zinc plating.

Specifically, we investigated the zinc electrodeposition process on a polycrystalline gold disc in contact with a Zn-cyanocomplex bath, by monitoring the adsorption of the $\mathrm{CN}^{-}$ion. This study was carried on at three representative biases. (i) At $-700 \mathrm{mV}$, where electrodeposition does not occur, one resonance is found both in the absence and in the presence of dissolved $\mathrm{Zn}$ (II) cyanocomplexes. (ii) At $-920 \mathrm{mV}$, a zinc layer was deposited, giving rise to a surface Au-Zn alloy and, in correspondence, the SFG spectra were deconvoluted with two resonances, associated with the cyanide species adsorbed both on metallic gold and at zinc sites. (iii) At $-990 \mathrm{mV}$, a thicker zinc layer was deposited and only one resonance could be resolved, associated with cyanide adsorbed at metallic zinc sites. This resonance progressively looses intensity with time, suggesting cathodic desorption induced by the deposited zinc layer, anticipated in potential with respect to a bare Au surface.

Cyanide adsorption onto a polycrystalline zinc electrode in contact with a free- $\mathrm{CN}^{-}$based aqueous solution was studied at OCP $(-830 \mathrm{mV})$ and $-1250 \mathrm{mV}$. Due to the surface reactivity of zinc in these conditions, our data showed a low signal-to-noise ratio that nevertheless allowed to clearly resolve a single resonance, associated with adsorbed $\mathrm{CN}^{-}$.

These results demonstrate the possibility of employing in situ SFG to monitor adsorption processes at zinc electrodes with running cathodic and anodic faradaic reactions, thus paving the way to the molecular-level study of practically relevant modifications occurring at the zinc anodes during charge-discharge cycling of highly prospective zinc-based batteries.

\section{References}

[1] J. Fu, Z. P. Cano, M. G. Park, A. Yu, M. Fowler, Z. Chen, Adv. Mat., 2017, 29

[2] A. R. Mainar, O. Leonet, M. Bengoechea, I. Boyano, I. de Meatza, A. Kvasha, A. Guerfi, J. Alberto Blázquez, Int. J. Energy Res., 2016, 40, 1032-1049

[3] S. J. Banik, R. Akolkar, J. Electrochem. Soc., 2013, 160, D519-D523 
403 [4] K. E. K. Sun, T. K. A. Hoang, T. N. L. Doan, Y. Yu, X. Zhu, Y. Tian, P. Chen, ACS Appl. Mater.

404 Interfaces, 2017, 9, 9681-9687

405 [5] C. Ramírez, B. Bozzini, J. Calderón, Electrochem. Acta, 2017, 248, 270-280

406 [6] B. Bozzini, B. Busson, G. P. De Gaudenzi, L. D’Urzo, C. Mele, A. Tadjeddine, J. Electroanal.

407 Chem., 2007, 602, 61-69

408 [7] B. Bozzini, B. Busson, C. Humbert, C. Mele, P. Raffa, A. Tadjeddine, J. Electroanal. Chem., 2011, 602, 2040924

410 [8] B. Bozzini, B. Busson, G. P. De Gaudenzi, L. D’Urzo, C. Mele, A. Tadjeddine, Corr. Sci., 2007, 49, 23924112405

412 [9] J. Hedberg, S. Baldelli, C. Leygraf, J. Phys. Chem. Lett., 2010, 1, 1679-1682

413 [10] M. Corva, Z. Feng, C. Dri, F. Salvador, P. Bertoch, G. Comelli, E. Vesselli, Phys. Chem. Chem. Phys., $4142016,18,6763-6772$

415 [11] C. Humbert, B. Busson, C. Six. A. Gayral, M. Gruselle, F. Villain, A. Tadjeddine, J. Electroanal. Chem., 2008, $416 \quad 621,314-321$.

417 [12] A. G. Lambert, P. B. Davies, D. J. Neivandt, Appl. Spectr. Rev., 2005, 40, 103-145

418 [13] L. Dalstein, A. Revel, C. Humbert and B. Busson, J. Chem. Phys., 2018, 148, 134701 (8 pages)

419 [14] B. Busson and L. Dalstein, J. Chem. Phys., 2018, 149, 034701 (15 pages)

420 [15] B. Busson and L. Dalstein, J. Chem. Phys., 2018, 149, 154701 (13 pages)

421 [16] S. L. Chen, L. Fu, W. Gan, H. F. Wang, J. Chem. Phys., 2016, 144, 034704

422 [17] B. Bozzini, B. Busson, C. Mele, A. Tadjeddine, J. Appl. Electrochem., 2008, 38, 897-906

423 [18] B. Bozzini, B. Busson, G. P. De Gaudenzi, C. Mele, A. Tadjeddine, J. All. Comp., 2007, 427, 341-349

424 [19] A. Fanigliulo, B. Bozzini, Corr. Eng. Sci. Tech., 2003, 38, 228-234

425 [20] B. Bozzini, B. Busson, G. P. De Gaudenzi, C. Mele, A. Tadjeddine, J. Sol. St. Electrochem., 2008, 12, 303$426 \quad 313$

427 [21] B. Bozzini, A. Fanigliulo, J. Appl. Electrochem., 2002, 32, 1043-1048

428 [22] Md.A. Quaiyyum, A. Aramata, S. Moniwa, S. Taguchi, M. Enyo, J. Electroanal. Chem., 1994, 373, 61-66

429 [23] M. Nakamura, A. Aramata, A. Yamagishi, M. Taniguchi, J. Electroanal. Chem., 1998, 446, 227-231

430 [24] H.H. Hassan, Appl. Surf. Sci., 2001, 194, 201-209

431 [25] D.V. Lezous, US 3,905,833 - Sept. $16^{\text {th }}, 1975$

432 [26] B. Bozzini, C. Mele, V. Romanello, J. Electroanal. Chem., 2006, 592, 25-30

433 [27] M. Pourbaix. Atlas of Electrochemical Equilibria I Aqueous Solutions, NACE International and 434 CEBELCOR, 1974, pp. 100-145, 168-175.

435 [28] W. Lu, C. Xie, H. Zhang and X. Li, ChemSusChem, 2018, 11, 3996-4006. 

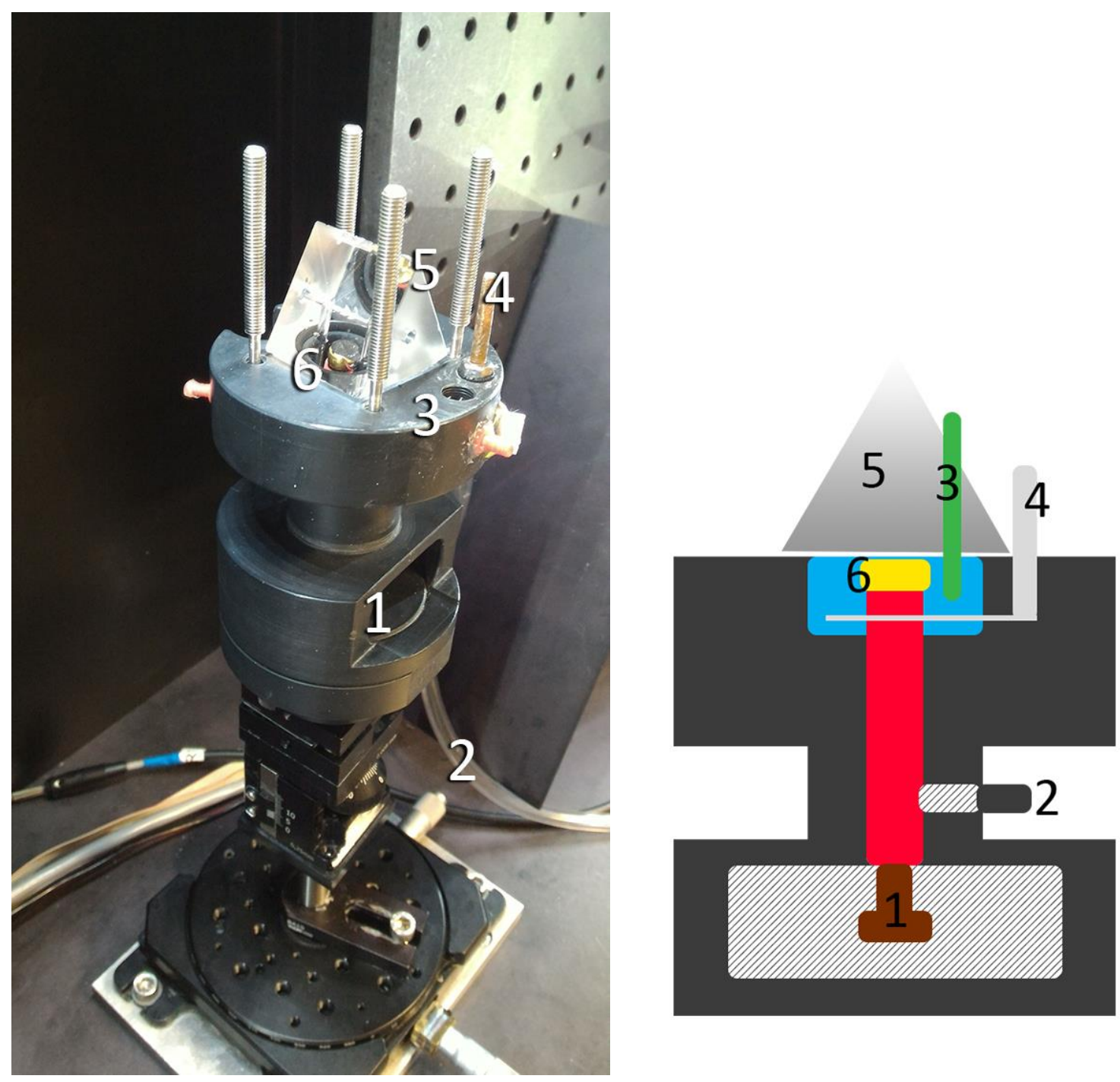

Figure 1 - a) Photograph of the cell assembled on the sample holder. 1) WE electrode contact cavity. 2) Vacuum pump tube. 3) RE electrode contact cavity. 4) AUX electrode contact. 5) $\mathrm{CaF}_{2}$ prism. 6) Electrolyte cavity. The sample is also visible. b) Scheme of the cell. Numeration is the same as a). 


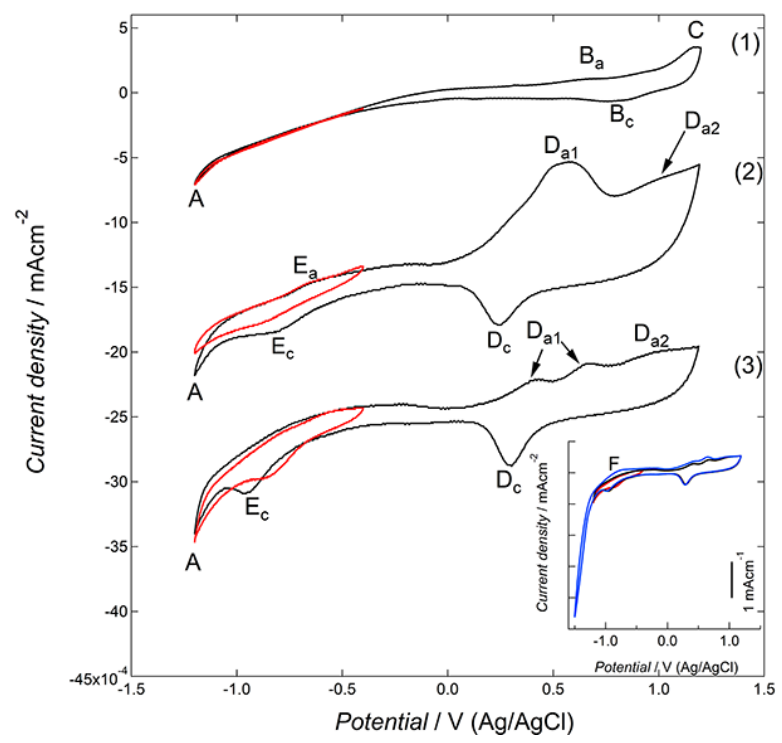

Figure 2 - CV for polycrystalline Au electrode in contact with the following aqueous solution: (1) $0.1 \mathrm{M} \mathrm{NaClO}_{4}$; (2) $0.1 \mathrm{NaClO}_{4}, 25 \mathrm{mM} \mathrm{KCN}$; (3) $0.1 \mathrm{NaClO}_{4}, \mathrm{mM} \mathrm{KCN}, \mathrm{mM} \mathrm{ZnO}$. Red curves indicate the potential range specifically investigated in the SFG experiments, black curves indicate the electrochemical behaviour of $\mathrm{Au}$ spanning both cathodic and anodic conditions. Inset: same conditions as in plot (3) of Panel (a), but with wider cathodic range (blue curve). Scan rate: $100 \mathrm{mV} \mathrm{s}^{-1}$.

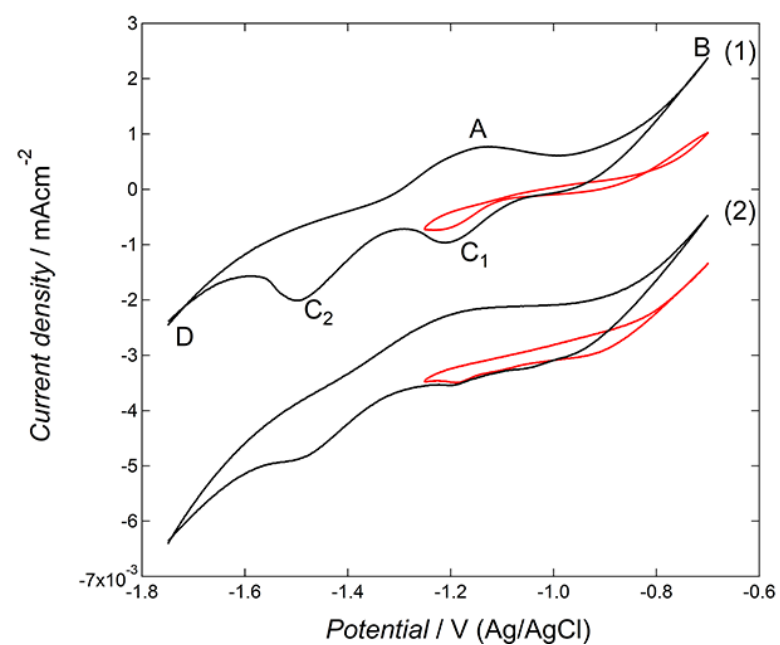

Figure 3 - CV for polycrystalline Zn electrode in contact with the following aqueous solution: (1) $0.1 \mathrm{M} \mathrm{NaClO4}$; (2) $0.1 \mathrm{NaClO} 4,25 \mathrm{mM} \mathrm{KCN}$. Scan rate: $100 \mathrm{mV} \mathrm{s}^{-1}$. Red curves indicate the potential range specifically investigated in the SFG experiments, black curves indicate the electrochemical behaviour of Au spanning 455 both cathodic and anodic conditions. 

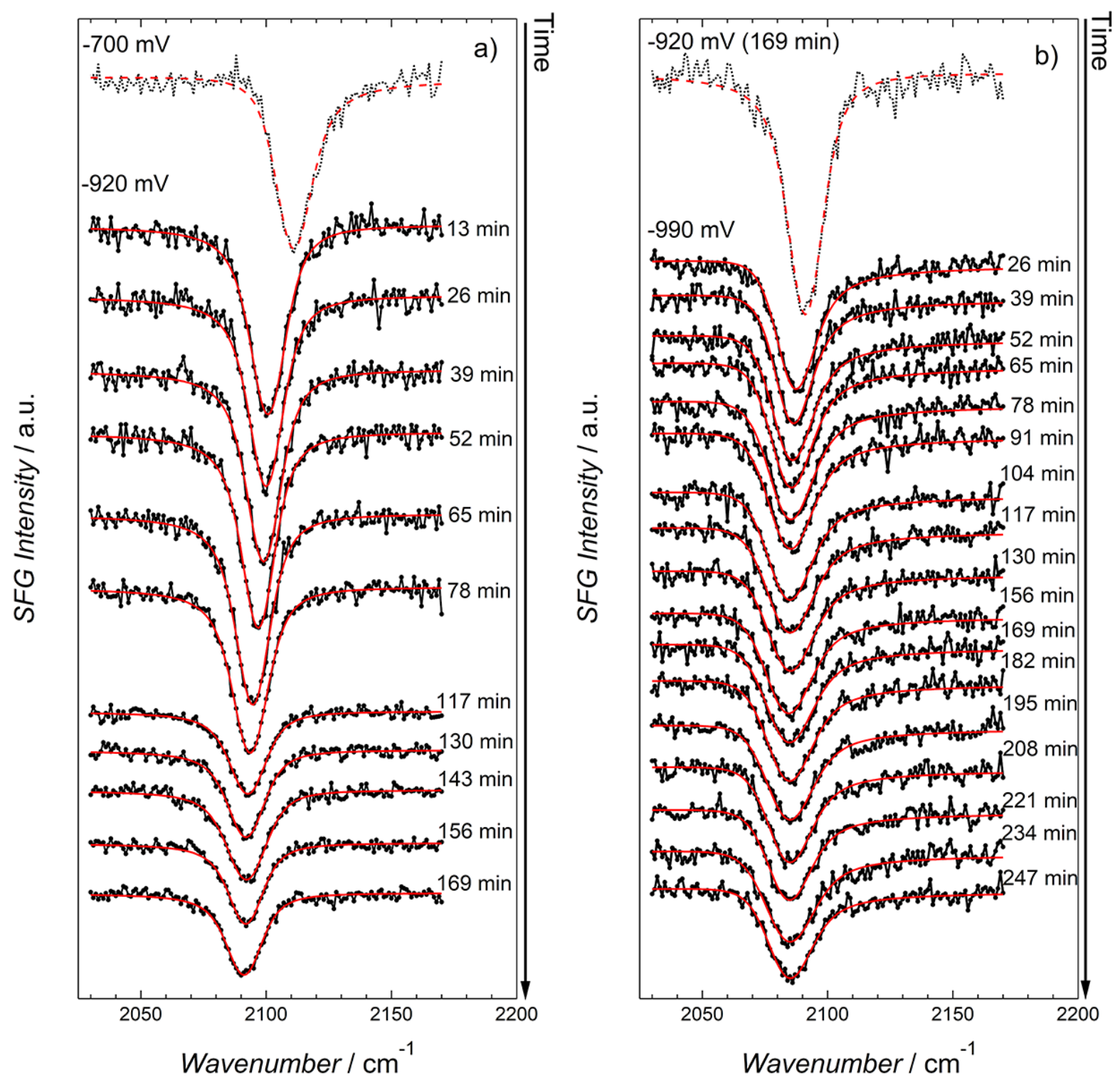

Figure 4 - SFG spectra in the $\mathrm{CN}^{-}$stretching region collected at $\mathrm{V}_{\text {bias }}=-920$ (Panel (a)) and -990 (Panel (b)) $\mathrm{mV}$ vs $\mathrm{Ag} / \mathrm{AgCl}$ as function of time. At the top of Panel (a) we report a representative spectrum measured at $-700 \mathrm{mV}$ vs $\mathrm{Ag} / \mathrm{AgCl}$ : in these conditions no evolution of the spectra was observed with time. At the top of Panel (b), for reference, we show the last spectrum measured at $-920 \mathrm{mV}$ vs $\mathrm{Ag} / \mathrm{AgCl}$ (169 min after the application of bias). The best-fit (red line) of the data (black, dotted line) is shown for each spectrum. 

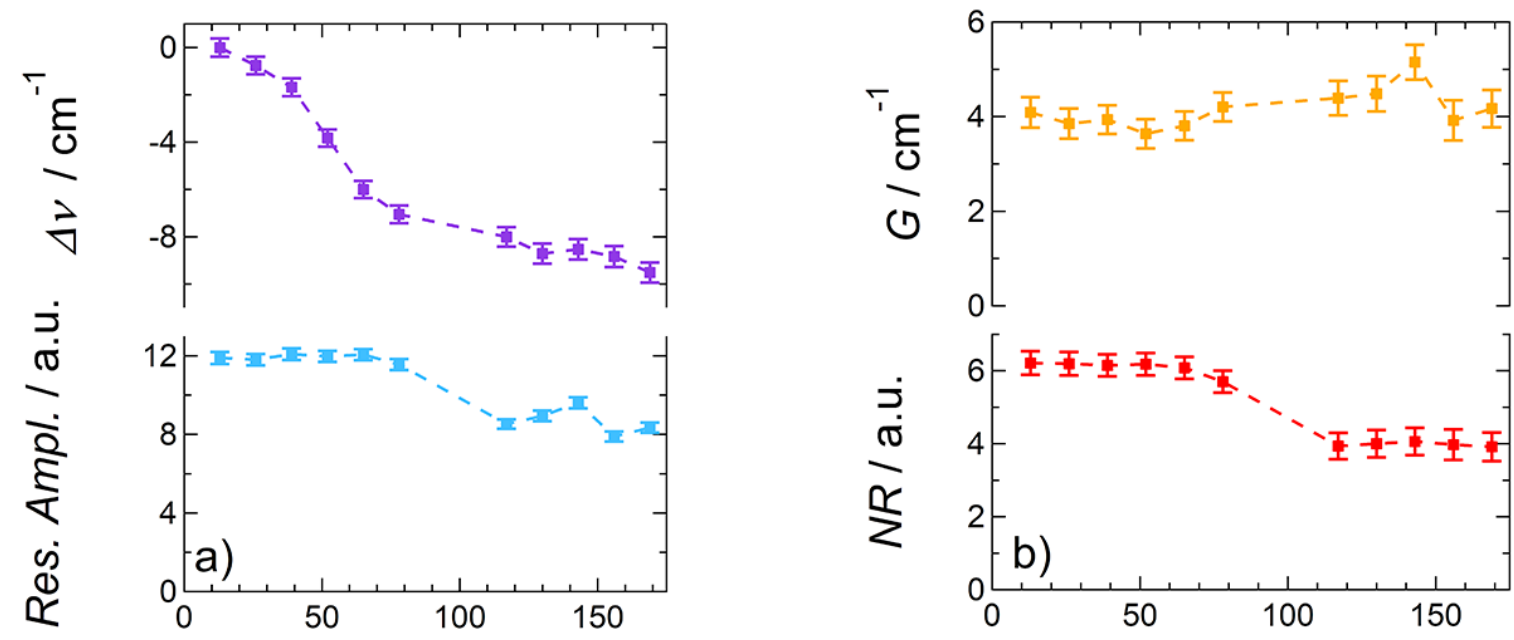

Time / min
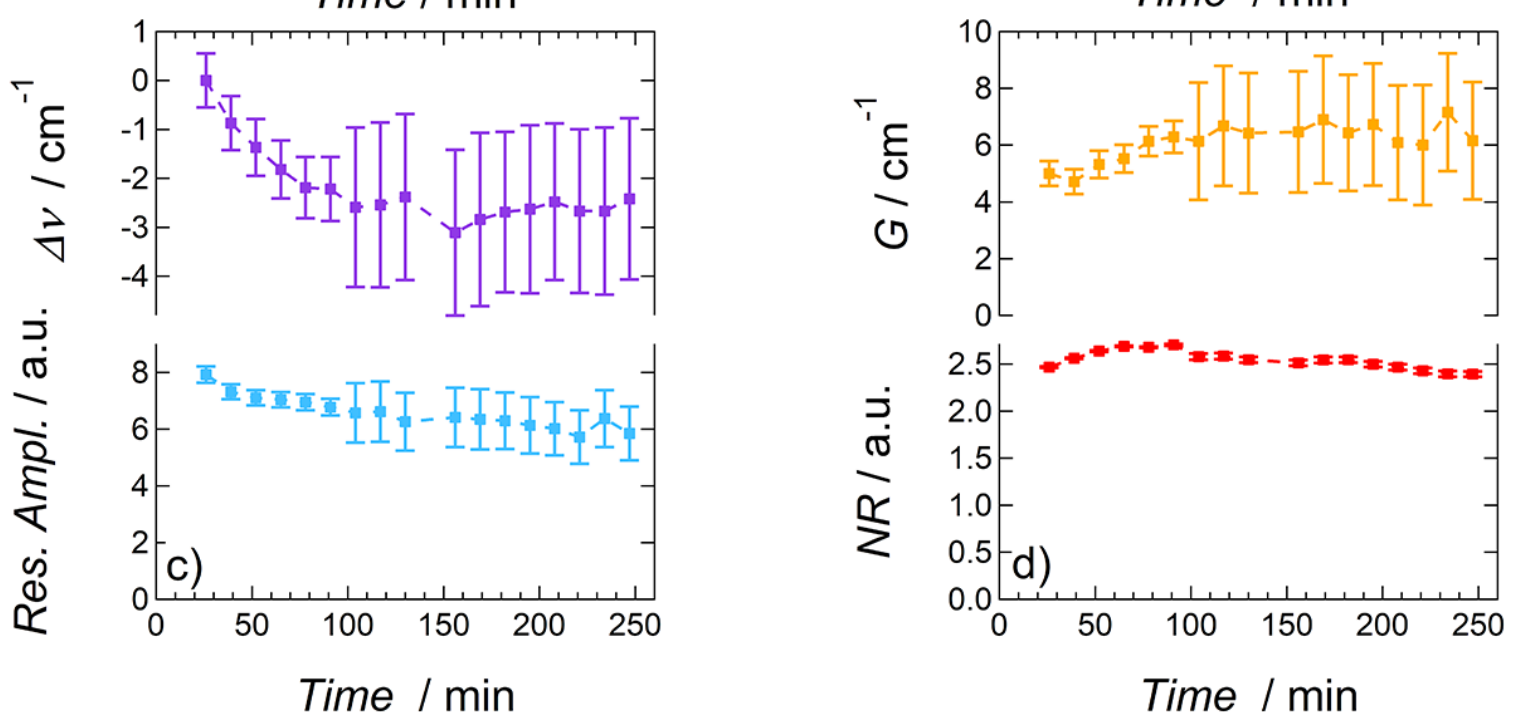

Time / min

Figure 5 - Resonant position shift $\left(\Delta v=v(t)-v_{0}\right)$, resonant amplitude, gaussian parameter $(G)$ and non-resonant amplitude (NR) associated with the corresponding to $\mathrm{CN}^{-}$adsorbed on Au as a function of time obtained by fitting the spectra measured at -920 (Panels (a, b)) and $-990 \mathrm{mV}$ vs Ag/AgCl (Panels (c, d)). 

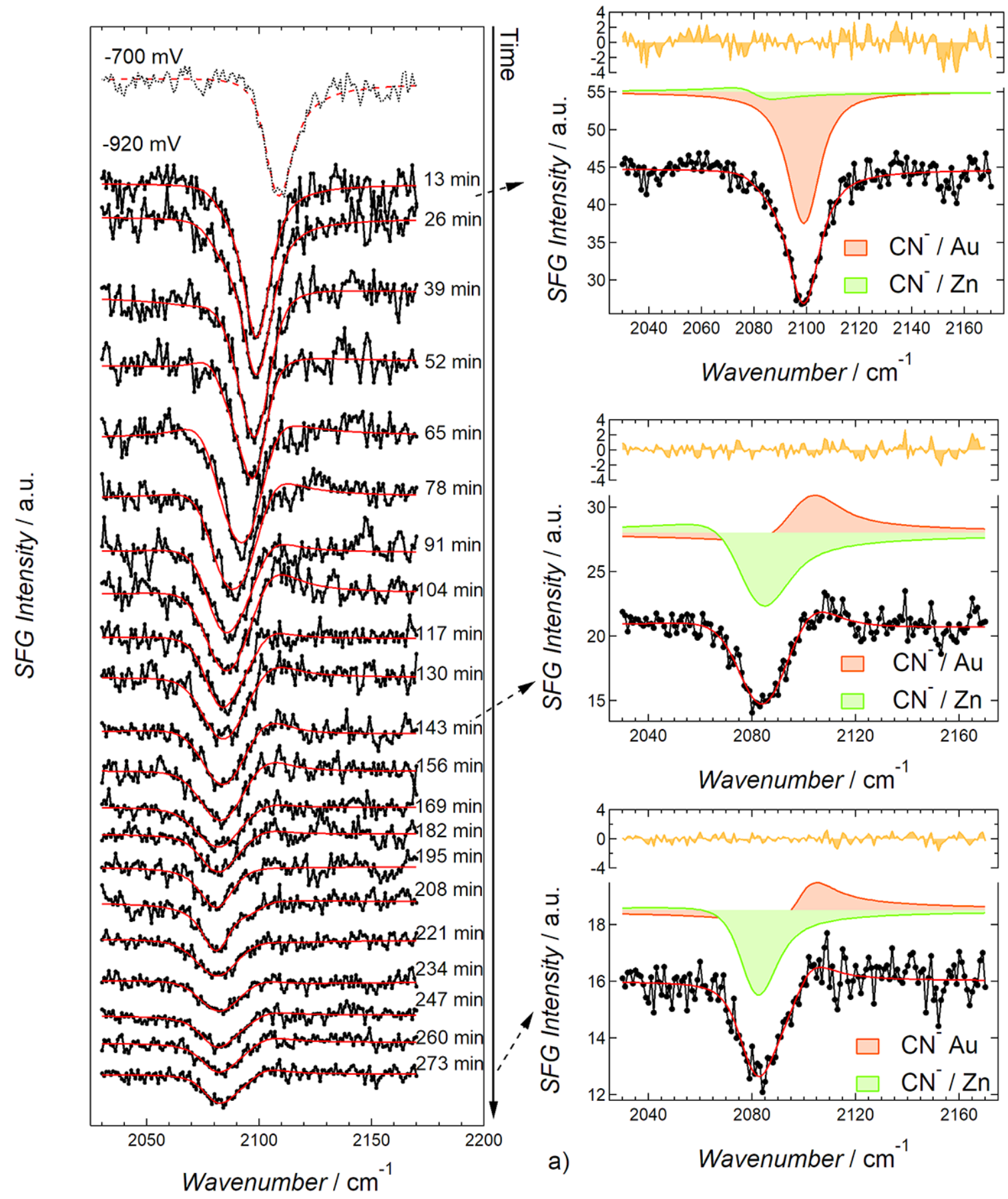

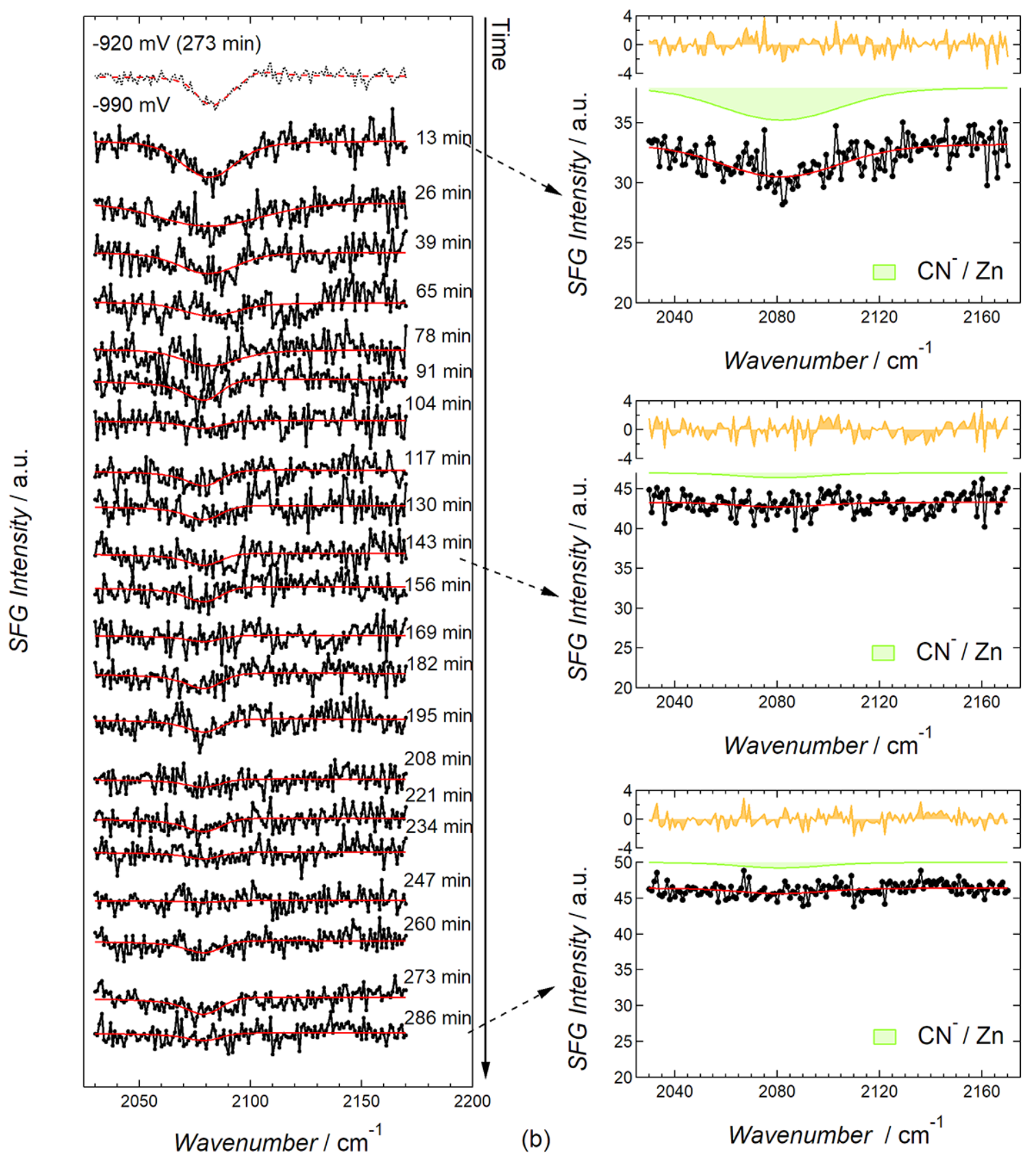

Figure 6 - SFG spectra in the $\mathrm{CN}^{-}$stretching region collected at $\mathrm{V}_{\text {bias }}=-700,-920 \mathrm{mV}$ (Panel (a) and $-990 \mathrm{mV}$ (Panel (b)) vs $\mathrm{Ag} / \mathrm{AgCl}$ as a function of time. The best-fit (red line) of the data (dotted line) is shown. On the right side, three illustrative spectra of the series are depicted (black dotted lines), together with the related best-fit (red line), the deconvoluted components (color-filled profiles) and the residual (dark-yellow filled profile). 

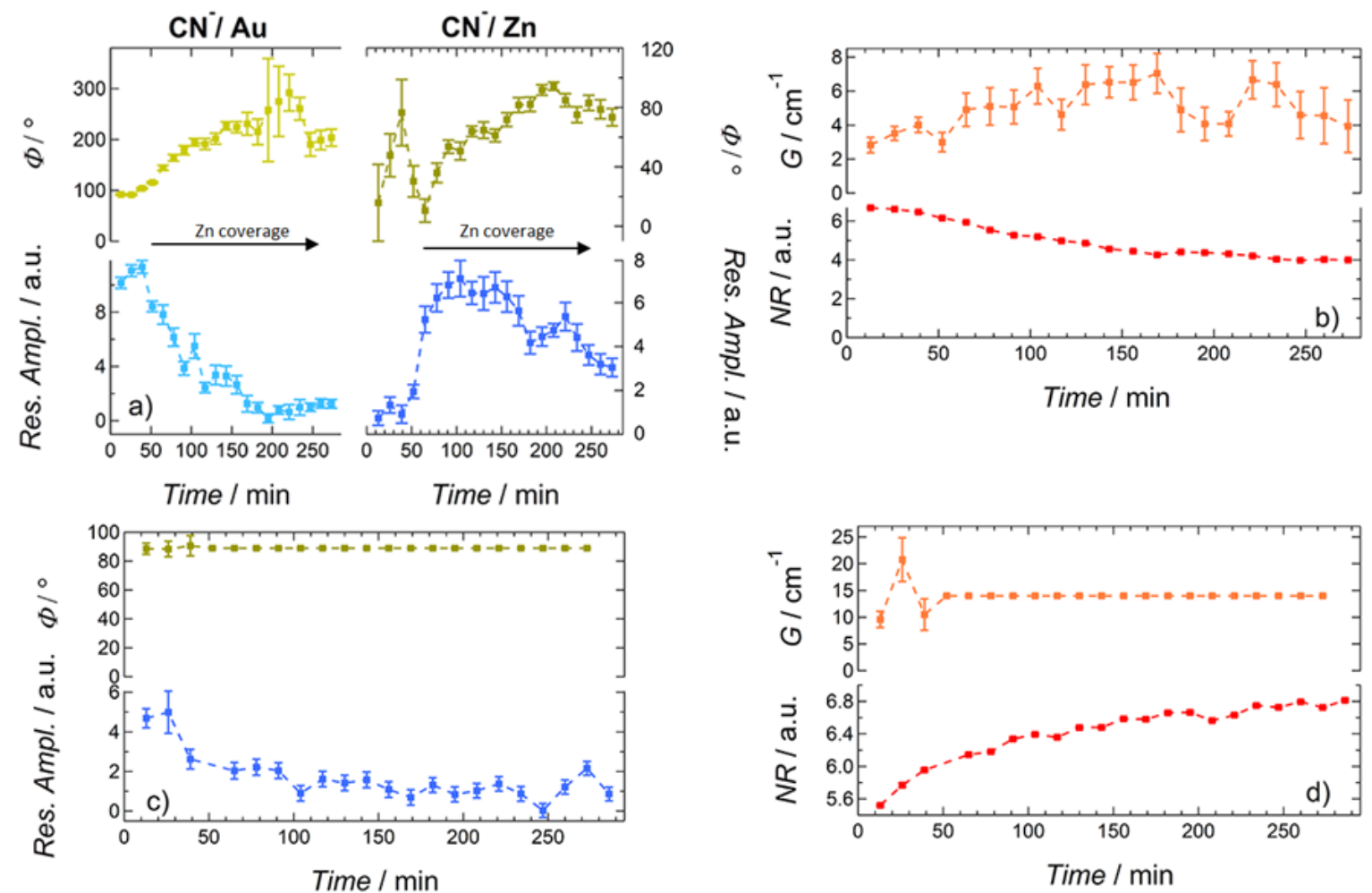

480 481

Figure 7 - Phase $(\phi)$, resonant amplitude, gaussian parameter (G) and non-resonant amplitude (NR) associated with adsorbed $\mathrm{CN}^{-}$resonances as a function of time, obtained by fitting the spectra measured at $-920 \mathrm{mV}$ vs Ag/AgCl (Panels (a, b)) and $-990 \mathrm{mV}$ vs Ag/ $\mathrm{AgCl}$ (Panels (c, d)). At $-920 \mathrm{mV}$ vs Ag/AgCl two kinds of resonances are found, corresponding to $\mathrm{CN}^{-}$adsorbed on $\mathrm{Au}-\left(\mathrm{CN}^{-} / \mathrm{Au}\right)$ and $\mathrm{Zn}$-sites $\left(\mathrm{CN}^{-} / \mathrm{Zn}\right)$.

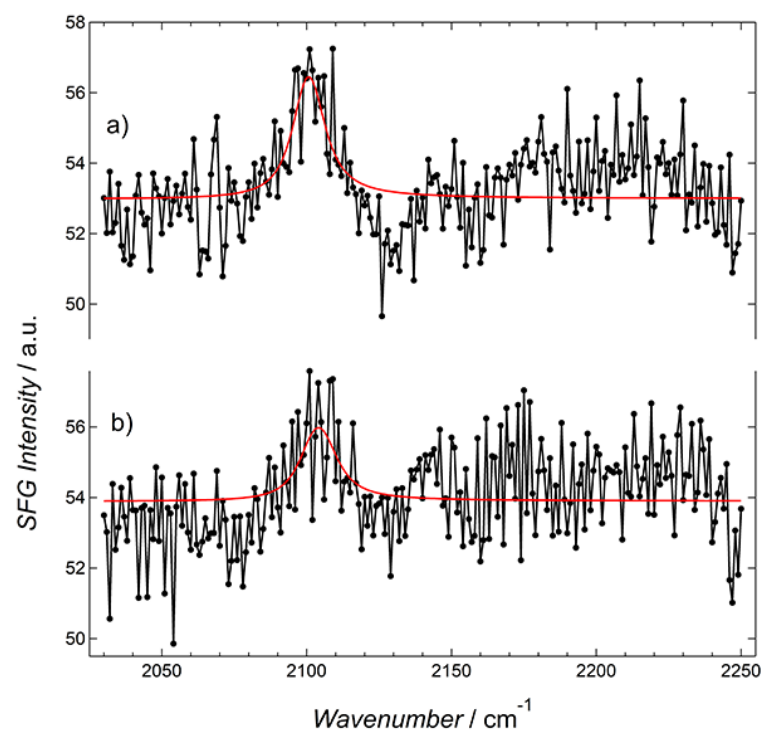

Figure 8 - SFG spectra in the $\mathrm{CN}^{-}$stretching region (black dotted lines) collected at: a) OCP (-830 $\mathrm{mV}$ vs $\mathrm{Ag} / \mathrm{AgCl}$ ), b) $\mathrm{V}_{\text {bias }}=-1.25 \mathrm{~V}$ vs Ag/AgCl with the respective fits (red lines). 